the more lasting effects of pain relief is suggested, even though all sizes of fibres sustain some damage.

\section{Summary and Conclusions}

The neurotoxicity of ethoglucid given by arterial perfusion has been investigated in dogs in order to study the histological basis of the various effects noted in clinical practice.

A direct toxic effect on nerve fibres of all types was found, and, in addition, damage to muscle and skin in the infused area was observed. A greater proportion of these effects appears to be reversible.

The results support the hypothesis that relief of pain is primarily the result of damage to pain-nerve fibres, which occurs rapidly after administration of the drug, but they offer no definite explanation why this relief tends to persist while other neurological effects subside, although a theoretical possibility is discussed.

The value of ethoglucid in the treatment of advanced malignant disease depends on its pain-relieving effect as well as its cytotoxic properties.
Our thanks are due to Mr. F. D. Naylor for his assistance with the experiments and to $\mathrm{Mr}$. $\mathrm{K}$. Horton for preparing the histological sections. The ethoglucid used in this study was supplied by I.C.I., to whom we are grateful. The work was carried out while one of us (M. R. B.) was in receipt of a British Empire Cancer Campaign Research Grant, and for this support we are indebted.

\section{REFERENCES}

Baxter, D. W., and Schacherl, U. (1962). Canad. med. Ass. 7., 86, 1200. Berry, K., Olszewski, J. (1963). Neurology (Minneap.), 13, 152.

Bond, M. R., Clarke, S. D., and Neal, F. E. (1964). Brit. med. F., 1, 951. Boone, S. C., and Woodhall, B. (1964). F. surg. Res., 4, 413.

Hanna, D. C., Gaisford, J. C., and Goldwyn, R. M. (1963). Amer. Y. Surg., 106, 783 .

Mahaley, M. S., and Woodhall, B. (1962). Cancer Chemother. Rep., 16, 543.

Sholes, D. M. (1960). Amer. F. Obstet. Gynec., 80, 481.

Smith, M. C. (1964). Brit. F. Anaesth., 36, 387.

Stewart, W. A., and Lourie, H. (1963). Ұ. Neurosurg., $20,64$.

Westbury, G. (1962). Proc. roy. Soc. Med., 55, 643.

- (1963). Ibid., 56, 655.

Woodhall, B., Mahaley, M. S., jun., Boone, S., and Huneycutt, H. (1962). f. surg. Res., 2, 373.

Pickrell, K. L., Georgiade, N. G., Mahaley, M. S., jun., and Dukes, H. T. (1960). Ann. Surg., 151, 750.

\title{
Improving the Reliability of the Rebreathing Method for Measuring Mixed Venous $\mathbf{P C O}_{2}$
}

\author{
SIMON GODFREY,* M.B., M.R.C.P.
}

Brit. med. F., 1965, 1, 1163-1165

A rebreathing method for measuring mixed venous $\mathrm{PCO}_{2}$, suitable for clinical use, was described by Campbell and Howell (1960a, 1960b, 1962), employing a principle probably first introduced by Plesch (1909). The present paper is based upon experience gained in the everyday use of the method, and suggests a modification to obtain the maximum accuracy with minimum discomfort to the patient.

Briefly, the standard procedure advised by Campbell and Howell (1962) consists of a first stage of rebreathing from a bag of oxygen of not more than two or three times the tidal volume for a period of 90 seconds. This usually produces a bag $\mathrm{PCO}_{2}$ a little above mixed venous $\mathrm{PCO}_{2}$ (Campbell and Howell, $1960 \mathrm{~b})$. After a rest of at least two minutes the second stage consists in rebreathing the prepared mixture for 20 seconds. During this second stage small differences between mixed venous and bag $\mathrm{PCO}_{2}$ are usually eliminated. In their papers Campbell and Howell have commented that various changes in the procedure may be necessary with some patients, but these manœuvres are rarely employed in normal clinical practice.

The main problems which have been encountered with the standard method are: (1) many subjects become very uncomfortable after 90 seconds of rebreathing from a small bag, however persuasive the operator; and (2) although Campbell and Howell have suggested a checking procedure it is not

* Medical Unit, Brompton Hospital, London. Present address : Department of Physiology, London Hospital Medical College, London E.1. routinely performed, and with inexperienced operators gross errors have been found through some fault in technique which has escaped notice.

In order to overcome these difficulties various modifications of the technique have been examined. In particular, the need for an arbitrary time for the first stage has been queried, and a routine checking procedure has been sought.

Personal experience showed that during the first stage a stimulus to breathing was noticed when the bag $\mathrm{PCO}_{2}$ was close to arterial blood $\mathrm{PCO}_{2}$. It therefore seemed that the discomfort during rebreathing was probably part of a $\mathrm{CO}_{2}$ response. Preliminary experiments showed that if the rebreathing was terminated about 10 to 15 seconds after the response was noted the bag $\mathrm{PCO}_{2}$ was a little above mixed venous $\mathrm{PCO}_{2}$.

The second stage of the rebreathing procedure can be regarded as the "fine adjustment" of a bag $\mathrm{PCO}_{2}$ which is already close to mixed venous levels. The gas is rebreathed for 20 seconds, during which time any differences between bag and mixed venous $\mathrm{PCO}_{2}$ should be eliminated, before much blood with an elevated $\mathrm{PCO}_{2}$ has had time to recirculate. In fact, recirculation of blood does mean that the bag $\mathrm{PCO}_{2}$ after 20 seconds is a little too high, but this is of no clinical significance. The only way to obtain a completely accurate result is to scan the record from a rapid $\mathrm{CO}_{2}$ analyser and look for a plateau in the $\mathrm{CO}_{2}$ concentrations of gas passing back and forth from mouth to bag (Collier, 1956). A comparison of the $\mathrm{PcO}_{2}$ obtained after 20 seconds of rebreathing from a bag close to 
mixed venous $\mathrm{PCO}_{2}$, with the plateau $\mathrm{PCO}_{2}$ obtained in this way, shows that the 20 -second $\mathrm{PCO}_{2}$ is about 1 to $2 \mathrm{~mm}$. $\mathrm{Hg}$ higher. Both figures are constant with repeated rebreathing periods (personal observations).

Neglecting the small error due to recirculation, if the bag $\mathrm{PCO}_{2}$ is the same as mixed venous $\mathrm{PCO}_{2}$, then no change will occur in its composition during the 20 seconds of rebreathing. This has been found to be true even in subjects with large dead spaces.

\section{Procedure}

Applying the principles discussed above, studies were made of 19 patients with various respiratory diseases and one normal subject.

Each subject rebreathed $100 \%$ oxygen from a bag containing three times his normal tidal volume. The first stage was continued until about 10 seconds after a definite change in the depth or rate of respiration was noted. The gas in the bag was sampled and its $\mathrm{CO}_{2}$ content was estimated with a modified Haldane apparatus (Campbell, 1960).

The second stage was begun after a rest of at least two minutes. The subject rebreathed the prepared bag for 20 seconds and its $\mathrm{CO}_{2}$ content was again determined. After a further two-minute rest, the procedure was repeated. This

TABLB I.-Illustrative Result of Rebreathing Procedure. Arterial Pco, Measured Directly is Also Shown

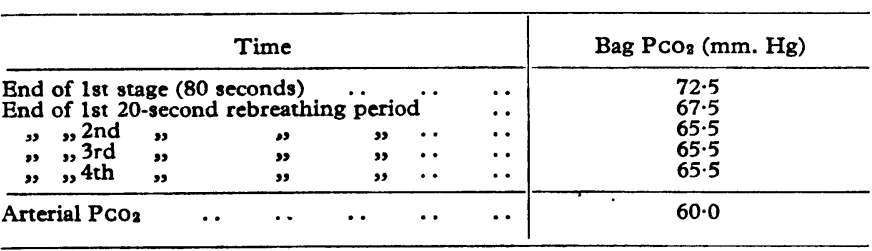

TABLE II.-Clinical Details and Results

\begin{tabular}{|c|c|c|c|c|c|c|}
\hline Subject & Díagnosis & Age & $\begin{array}{l}\text { Time for } \\
\text { First } \\
\text { Strage } \\
\text { (secs.) }\end{array}$ & $\begin{array}{l}\text { No. of } \\
20-\text { sec. } \\
\text { Periods }\end{array}$ & $\begin{array}{c}\text { Mixed } \\
\text { Venous } \\
\text { Pco } \\
\text { (mm. Hg) }\end{array}$ & $\begin{array}{c}\text { Arterial } \\
\mathrm{PCO}_{2} \\
\text { (mm. } \mathrm{Hg} \text { ) }\end{array}$ \\
\hline $\begin{array}{r}1 \\
2 \\
3 \\
4 \\
5 \\
6 \\
7 \\
8 \\
9 \\
10 \\
11 \\
12 \\
13 \\
14 \\
15 \\
16 \\
17 \\
18 \\
19 \\
20\end{array}$ & $\begin{array}{l}\text { E. } \\
\text { D. I. P. F. } \\
\text { Bronchiectasis } \\
\text { C. B. \& A. } \\
\text { C. B. \& B. } \\
\text { C. B. \& E. } \\
\text { E. B. } \\
\text { C. B. } \\
\text { C. B. \& E. } \\
\text { E. B. } \\
\text { A. } \\
\text { Normal } \\
\text { A. } \\
\text { C. B. } \\
\text { Sarcoid } \\
\text { C. B. } \\
\text { D. I. P. F. } \\
\text { E. }\end{array}$ & $\begin{array}{l}62 \\
52 \\
70 \\
57 \\
60 \\
59 \\
48 \\
69 \\
60 \\
70 \\
42 \\
27 \\
25 \\
45 \\
63 \\
64 \\
46 \\
70 \\
50 \\
56\end{array}$ & $\begin{array}{r}90 \\
60 \\
60 \\
100 \\
80 \\
75 \\
80 \\
90 \\
100 \\
65 \\
80 \\
55 \\
40 \\
60 \\
90 \\
105 \\
65 \\
70 \\
50 \\
120\end{array}$ & $\begin{array}{l}3 \\
4 \\
2 \\
5 \\
3 \\
2 \\
5 \\
2 \\
2 \\
3 \\
2 \\
3 \\
3 \\
3 \\
3 \\
2 \\
4 \\
2 \\
2 \\
4\end{array}$ & $\begin{array}{l}47.8 \\
45.5 \\
58.5 \\
49.0 \\
65.6 \\
65.7 \\
58.5 \\
57.1 \\
54.2 \\
74 \cdot 3 \\
44.2 \\
42.8 \\
50.7 \\
43.5 \\
57.1 \\
80.0 \\
52.1 \\
67.8 \\
48.5 \\
51.4\end{array}$ & $\begin{array}{l}38.0 \\
= \\
60 \cdot 0 \\
55 \cdot 0 \\
\overline{46 \cdot 0} \\
\overline{41 \cdot 0} \\
\overline{45 \cdot 0} \\
\overline{50 \cdot 0} \\
48 \cdot 0 \\
64 \cdot 0 \\
43.0\end{array}$ \\
\hline
\end{tabular}

Note: E. $=$ Emphysema. C. B. $=$ Chronic bronchitis. A. $=$ Asthma. D. I. P. F. $=$ Diffuse interstitial pulmonary fibrosis

second stage of rebreathing periods was continued until the bag $\mathrm{PCO}_{2}$ remained unchanged by 20 seconds of rebreathing. This constant level was taken as the mixed venous $\mathrm{PCO}_{2}$. The level was accepted as constant if readings differed by less than $\pm 0.1 \% \mathrm{CO}_{2}$ (equivalent to a $\mathrm{PCO}_{2}$ of $0.72 \mathrm{~mm}$. $\mathrm{Hg}$ ), which has been found to be within the limits of accuracy of the estimation (Campbell, 1960).

In 10 subjects arterial blood was sampled between three and six minutes after the end of the rebreathing procedure. The arterial $\mathrm{PCO}_{2}$ was measured with a Severinghaus electrode. All subjects were at rest throughout the whole procedure.

\section{Results}

In order to illustrate the kind of results obtained, the readings for one patient are shown in Table I. It can be seen that, once the constant $\mathrm{PCO}_{2}$ level was reached, two further 20 -second rebreathing periods did not cause any change. In other subjects as many as five consecutive 20-second periods have not affected the bag $\mathrm{PCO}_{2}$.

The clinical details and results in all 20 subjects are shown in Table II. The duration of the first stage varied from 40 to 120 seconds, with an average of 76.8 seconds (S.D. $=20$ seconds). In every case the bag $\mathrm{PCO}_{2}$ at the end of the first stage was a few $\mathrm{mm}$. $\mathrm{Hg}$ higher than the constant level obtained in the second stage. This constant level of bag $\mathrm{PCO}_{2}$ was always obtained after repeated 20 -second rebreathing periods, the average number of such periods required being three.

In the 10 subjects upon whom arterial punctures were performed the average difference between arterial and mixed venous $\mathrm{PCO}_{2}$ was $5.4 \mathrm{~mm}$. $\mathrm{Hg}$ (S.D. 1.6 , range +3.2 to +8.2 $\mathrm{mm} . \mathrm{Hg}$ ).

\section{Discussion}

The object of this investigation was to find a comfortable, accurate, and reliable method for the bedside measurement of mixed venous $\mathrm{PCO}_{2}$. $\mathrm{By}$ allowing the subject to terminate the first stage at the beginning of the $\mathrm{CO}_{2}$ response, the dyspnoea of a severe $\mathrm{CO}_{2}$ stimulus was avoided. It is quite clear from the results that the rebreathing time required in the first stage to reach approximately mixed venous $\mathrm{PCO}_{2}$ levels varies considerably, and it is therefore better to allow the $\mathrm{CO}_{2}$ response to signal the end of this stage than to choose an arbitrary time. However, if there is doubt of the patient's ability to increase his ventilation-for example, if the patient is unconscious or paralysed-an arbitrary time of, say, 80 to 90 seconds will be needed for the first stage. Any errors incurred will have to be eliminated in the second stage.

The repetition of the 20 -second rebreathing periods of the second stage increases the total duration of the investigation by about five minutes but is a valuable check on the results. If any gross error has occurred in the first stage these periods will eliminate it, and, provided they are repeated until a constant value is obtained, the end-result will be accurate. The fact that results agree also serves as a check on the sampling and analysis procedure.

In the present investigation the average arteriovenous $\mathrm{PCO}_{2}$ difference was found to be $5.4 \mathrm{~mm}$. $\mathrm{Hg}$. This is a little lower than the $6 \mathrm{~mm}$. Hg found by most investigators (Hackney, Sears, and Collier, 1958 ; Campbell and Howell, 1960b), but the series is rather small and the difference is probably within the range of experimental error.

During the investigation the possibility of using larger bag volumes was considered. Employing bags of between 5 and 10 times the subject's tidal volume, it was found that the first stage needed to be considerably longer, but the number of 20-second periods required for the second stage was much the same. It was concluded, in agreement with Campbell and Howell (1962), that the smaller bag gave better results.

\section{Proposed Technique}

The following method, based upon the work described above, is offered as an accurate bedside procedure for measuring mixed venous $\mathrm{PCO}_{2}$, without distressing the patient.

Selection of Bag Volume.-The patient breathes quietly with the mouthpiece tap open to the air and the bag empty. The tap is then switched back and forth to catch three expirations in the bag and its size is noted. The expired air is then emptied out and the bag is filled to the same volume 
with oxygen. This can be judged accurately enough if the total bag capacity is not more than about 2 litres.

Stage 1-Preparation of the Bag.-The bag of oxygen is rebreathed until an increase is noted in the depth or rate of respiration. About 10 seconds' more rebreathing is encouraged and the first stage is terminated.

Stage 2-Fine Adjustment.-After at least two minutes the prepared bag is rebreathed for 20 seconds and its $\mathrm{PcO}_{2}$ is measured. After a further two-minutes rest (about the time required to analyse the previous sample of gas), the 20 -second rebreathing period is repeated. This procedure is continued until the bag $\mathrm{PCO}_{2}$ remains unaltered by the rebreathing. This value is taken as the mixed venous $\mathrm{PCO}_{2}$.

\section{Summary}

The problems encountered in the measurement of mixed venous $\mathrm{PCO}_{2}$ by the rebreathing method are discussed. An adaptation of the method is described which allows the use of small-bag volumes without distressing the patient. The time for the initial preparation of the bag is not fixed but depends upon the observation of a change in ventilation which is thought to be a $\mathrm{CO}_{2}$ response. The subsequent 20 -second rebreathing periods are repeated to ensure more accurate results. The application of the method to a group of patients is described and the findings are discussed.

I am extremely grateful to Dr. E. J. M. Campbell for introducing me to the study of $\mathrm{PCO}_{2}$ and for his helpful criticism and advice during this investigation. Professor J. G. Scadding, Dr. J. R. Bignall, and Dr. K. M. Citron kindly allowed me to study patients under their care and read the manuscript. Dr. L. H. Capel provided facilities for studies with a rapid $\mathrm{CO}_{2}$ analyser and Dr. E. $N$. O'Brien for estimation of arterial $\mathrm{PcO}_{2}$.

\section{RBFERENCES}

Campbell, E. J. M. (1960). Brit. med. F, 1, 457. Methods and Interpretations, edited by R. Woolmer. Churchill, London.

- (1960b). Brit. med. F., 1, 458.

(1962). Ibid., 2, 630.

Collier, C. R. (1956). 7., appl. Physiol., 9, 25.

Hackney, J. D. Sears, C. H., and Collier, C. R. (1958). Ibid., 12, 425.

Plesch, J. (1909). Z. exp. Path. Ther., 6, 484.
A 79-year-old woman was on her way to play bridge when she developed severe central chest pain while struggling to open a lift door. She collapsed and was taken to the casualty department of this hospital. The pain was very severe and was also felt in the left side of the abdomen. Later she gave a history of a previous attack of severe chest pain one week earlier; this earlier chest

- From the Cardiac Department, St. George's Hospital, London. Present address: Department of the Regius Professor of Medicine, Radcliffe Infirmary, Oxford. pain had been situated behind the xiphisternum and through to the back, but not below the diaphragm.

On first examination in the casualty department she was in severe pain and complaining of thirst ; she was shocked and sweating, but had a blood-pressure of $110 / 70$. The pulse rate was 96 The jugular venous pressure (J.V.P.) was raised to the angle of the jaw. The heart sounds were normal ; no murmurs were heard. The arterial pulses were all present and equal. The liver was palpable with an enlarged right lobe, but the abdomen was soft and normal bowel sounds were heard. Neurological examination was negative.

An electrocardiogram (E.C.G.) (Fig. 1) showed minimal ST segment depression and T-wave inversion in leads I, II, AVL, V4V7, but was otherwise normal. The systolic blood-pressure rapidly fell to $40-50 \mathrm{~mm}$. $\mathrm{Hg}$, but the pulse rate remained inappropriately low with a sinus rate of $80 / \mathrm{min}$. The J.V.P. was measured (with an intravenous catheter) at $+8 \mathrm{~cm}$. of saline above the sternal angle.

She was given morphine (15 mg.) intravenously and continuous oxygen by mask. She became stuporous, with Cheyne-Stokes

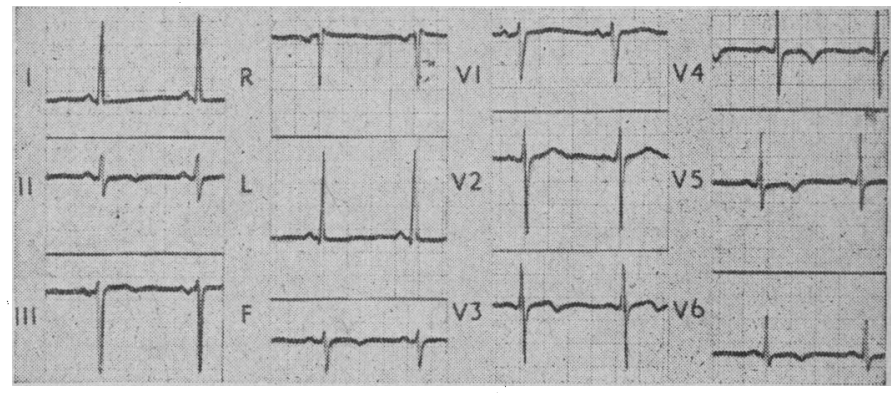

Fig 1.-E.C.G showing non-specific $T$ inversion V4-V6. 